\title{
A Genetic Algorithm Based Approach to the Profitable Tour Problem with Pick-up and Delivery
}

\author{
Hae Kyeong Lee \\ Department of Industrial and Management Engineering, Kyungsung University \\ 314-79 Daeyeon-3 dong, Nam-gu, Busan 608-736, Korea \\ Email: hshklee@naver.com \\ Friska Natalia Ferdinand \\ Department of Industrial and Management Engineering, Kyungsung University \\ 314-79 Daeyeon-3 dong, Nam-gu, Busan 608-736, Korea \\ Email: freezk_83@yahoo.com \\ Taioun Kim \\ Department of Industrial and Management Engineering, Kyungsung University \\ 314-79 Daeyeon-3 dong, Nam-gu, Busan 608-736, Korea \\ Email: twkim@ks.ac.kr \\ Chang Seong Ko ${ }^{\dagger}$ \\ Department of Industrial and Management Engineering, Kyungsung University \\ 314-79 Daeyeon-3 dong, Nam-gu, Busan 608-736, Korea \\ Email: csko@ks.ac.kr
}

Received, February 17, 2010; Revised, April 20, 201009; Accepted, May 17, 2010

\begin{abstract}
As express courier market expands rapidly, companies are exposed to fierce competition. To cope with struggle for their survival, they are continuously making efforts to improve their service system. Even if most of service centers are directly linked to a consolidation terminal in courier service network, some of them with regional disadvantages are operated in milk run type from/to the consolidation terminal, which is a traditional PDP (Pick-up and Delivery Problem). This study suggests an approach to solve the PDP with the objective of maximizing the incremental profit, which belongs to PTP (Profitable Tour Problem) class. After the PTP is converted to TSP (Traveling Salesman Problem) with the same objective, a heuristic algorithm based on GA (Genetic Algorithm) is developed and examined through an example problem in practice of a courier service company in Korea.
\end{abstract}

Keywords: Pick-up and Delivery Problem, Milk Run, Express Courier Service, Profitable Tour Problem, Traveling Salesman Problem, Genetic Algorithm

\section{INTRODUCTION}

As express courier market expands rapidly, companies are exposed to fierce competition. They are striving for providing superior service at a competitive price in order to remain competitive.

Most express courier service networks in Korea are typically operated as shown in Figure 1. An express courier service network consists of customer zones, service centers, and consolidation terminals. Customer zones refer to geographical districts in which customers either ship or receive packages and are covered by a service center. And a service center receives customer shipment requests and picks up parcels from customer zones and then they are collected before transshipped in bulk to a consolidation terminal. As such, the service center acts as a transshipment and temporary storage facility connecting customers to a consolidation terminal. At the consolidation terminal, consolidated packages are screened, sorted and then loaded onto delivery trucks for their destinations.

Even if most of service centers are directly linked

$\uparrow$ : Corresponding Author 


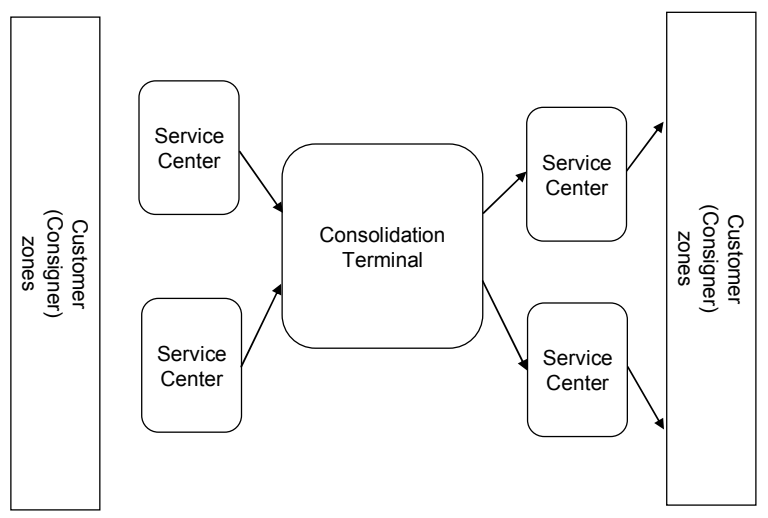

Figure 1. The shipment flows in a Korean express courier service network (Ko et al., 2007).

to a consolidation terminal in courier service networks, some of them with regional disadvantages are operated in milk run type from/to the consolidation terminal, which is a traditional PDP (Pick-up and Delivery Problem).

There have been a number of studies related to the design of service networks for express parcel deliveries. Powell and Sheffi (1983) initiated a load planning model linking a number of consolidation terminals. However, they did not consider links between terminals and customers. Similarly, Powell (1986) formulated the load planning problem for less-than-truckload (LTL) motor carriers as a fixed charge network design problem. On the other hand, Schneider et al. (1972) were among the first to determine the minimum cost location of urban consolidation terminals. Min (1994) extends this study to a consolidation terminal location-allocation problem considering both international and multiple objective aspects. These two studies, however, focused on the issues of location and direct shipment without considering the possibility of serving multiple customers on a single delivery tour.

Leung et al. (1990) presented a mathematical model and its solution procedure to solve point-to-point delivery problems. However, their study did not take cutoff time restrictions on consolidation into consideration in door-to-door service coverage problems. The study conducted by Cheung et al. (2001) was the first to examine a service network design problem encountered by express couriers such as DHL, Hong Kong. They proposed a hybrid optimization/simulation model that aimed to maximize service coverage and service reliability by adjusting cutoff time. Their study revealed that the extension of cutoff time led to a higher level of service coverage, while decreasing the service reliability. Recently, Ko et al. (2007) developed an integer programming model and a genetic algorithm to determine the cutoff time at each service center according to the spatial proximity of service centers to customers and the capacity of a consolidation terminal.
This study suggests an approach to solve the PDP with the objective of maximizing the incremental profit, which belongs to PTP (Profitable Tour Problem) class. After the PTP is converted to TSP (Traveling Salesman Problem) with the same objective, a heuristic algorithm based on GA (Genetic Algorithm) is developed and examined through an example problem in practice of a courier service company in Korea. The contribution of this paper resides in the fact that an actual situation of regional disadvantages in courier service network has been considered. Section 2 addresses problem definition and modeling of the problem. Section 3 presents algorithm development based on GA. Section 4 provides implementation results for the chosen domain. Section 5 describes analysis and discussion for the implementation. Conclusions are followed thereafter.

\section{PROBLEM DEFINITION}

It is typical in conventional studies to design the service network minimizing the cost of delivery with fixed revenue. However, this study deals with the design of express courier service network to maximize company's profit by adjusting delivery and pick-up times at a service center.

According to the classification by Bodin et. al. (1983), this study belongs to a typical PDP (Pick-up and Delivery Problem). The only difference is the objective function maximizing the revenue instead of minimizing the cost of delivery. However, PDP with sales (or profits) (PDPs) may also be interpreted as travelling salesman problem with sales (or profits) (TSPs). Related studies to TSPs are well summarized in Feillet et al. (2005), and they may be classified into one of the following three types:

First, a problem may be formalized as a PTP problem with the objective function of minimizing the travel cost minus collected profit (Dell'Amico, 1995). Second, an objective function may be setup to maximize the profit with the constraint limiting the cost of delivery, which may be viewed as an OP problem (Laporte and Martello, 1990; Kataoka and Morito, 1988). Finally, a PDPs problem may be equivalent to a PCTSP (prize-collecting TSP) where the objective function is to minimize the travel cost while limiting the amount of profit.

The objective suggested in this study is to find a tour maximizing incremental profit, and thus this study may be classified as one of the PTP.

In a typical service network, a consolidation terminal allocates packages to service centers and then allocated packages are delivered to customers. On the other hand, packages collected in the meantime are sent to the consolidation terminal. It is quite uneconomical to operate service centers with a small amount of package orders in the typical way. In that case, a line-haul vehicle from the consolidation terminal travels several small service centers. A small service center may also be stopped 
by within the network of larger service centers.

This study is to configure an express courier service network maximizing revenue under such circumstances mentioned above. It is quite obvious that larger revenue may be realized by extending the closing time of order reception. Customers appreciate the time extension because their packages may be delivered on the next day and a faster delivery also contributes to strengthening company's competitiveness.

Suppose that a line-haul vehicle travels around five service centers for pick-up and delivery from early times and packages are pick-up and delivered along the following travel route:

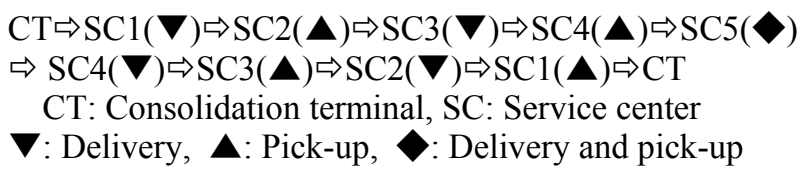

The goal is to reconfigure the route so that the profit is maximized. Each service center has two different nodes, one for delivery and the other for pick-up, and thus there are ten nodes for five service centers. Therefore, the problem can be viewed as a TSP departing from and returning to consolidation terminal with ten nodes visiting in the meantime, of which objective function is to maximize the total revenue. For SC 5 in the above example, package delivery and order pick-up are performed in a serial manner with zero travel distance.

Since constraints are equivalent to a TSP with two nodes for each service center, one may only need to define the objective function. Given the route of a tour, the total revenue and operating costs are easily obtained once travel times between service centers and operating times for each service center are known. The objective function in this study is to maximize the net profit which is calculated by subtracting incremental cost from incremental revenue instead of total revenue for TSPs with multiple service centers.

Thus, the objective function is defined as follows:

Maximize $\alpha \sum_{j=1}^{n}\left\{D_{j}\left(-\alpha_{j}\right) \cdot\left(\Delta d t_{j}\right)+P_{j} \cdot b_{j} \cdot\left(\Delta p t_{j}\right)\right\}-\beta(\Delta T)^{\gamma}$

where

$A$ incremental revenue per unit

$D_{j} \quad$ delivery amount per hour of service center $j$

$a_{j} \quad$ delivery type of service center $j$ which reflects the order characteristics such as residential, industrial, and commercial areas

$\Delta d t_{j}$ incremental increase in time required for delivery order in an updated tour compared to the current tour (unit: hour)

$P_{j} \quad$ pick-up amount per hour of service center $j$

$b_{j} \quad$ pick-up type of service center $j$

$\Delta p t_{j}$ incremental increase in time required for pickup order in an updated tour compared to the current tour(unit: hour)
$B$ incremental cost per hour according to increase of total tour time

$\Delta T$ incremental increase in total tour time for an updated tour compared to the current tour (unit: hour)

$\gamma \quad$ index reflecting the effect of tour time on tour cost

In Equation (1), an incremental revenue is due to an increase in collected profits by adjusting delivery and pick-up times while an incremental operating cost is incurred because of an increase in travel times. When calculating the operating cost, $(\Delta T)^{\gamma}$, where $\gamma$ is larger than or equal to one, instead of $(\Delta T)$ is used to prevent an excessive time increase which may affect operating times in the consolidation terminal. It is also assumed that consumed times in activities unrelated to package handling such as drivers mealtimes are negligible.

\section{ALGORITHM DEVELOPMENT}

The proposed model is regarded as a class of TSP with the objective of maximizing the incremental profit. There have been many studies regarding TSP applied to the area of logistics. Belonging to NP class, most of studies suggest heuristic algorithms considering the problem characteristic. Recently, several solution methodologies based on meta-heuristic, including GA and tabu search, have been introduced.

The first step of the proposed algorithm is to convert PTP with pick-up and delivery to TSPs. Suppose that there are $n$ service centers with pick-up and delivery, one may generate $n$ service centers with delivery only and $n$ service centers with pick-up only. Considering the linked consolidation terminal, PTP with $n$ service centers may be converted to a TSP with $(2 n+1)$ nodes. In other words, a service center $k$ in PTP generates two nodes in TSPs which are one delivery node $k$ and the other pick-up node $n+k$ if we assume that the terminal node is represented as node 0 .

After a PTP with $n$ service centers is converted to a TSP with $(2 n+1)$ nodes, GA approach is applied to solve it. GA is generally referred to as a stochastic solution search procedure which is proven to be useful for solving combinatorial problems using the concept of evolutionary computation imitating the natural selection and biological reproduction of animal species (Goldberg, 1989; Gen and Cheng, 2000).

The encoding of solutions in the proposed algorithm was designed to show that each solution is exactly represented by one chromosome and the decoding of each chromosome results in exactly one solution for the problem.

Let's consider a PTP with $n$ service centers and a consolidation terminal. It is firstly converted to a TSP with $(2 n+1)$ nodes. The chromosome is a string of 


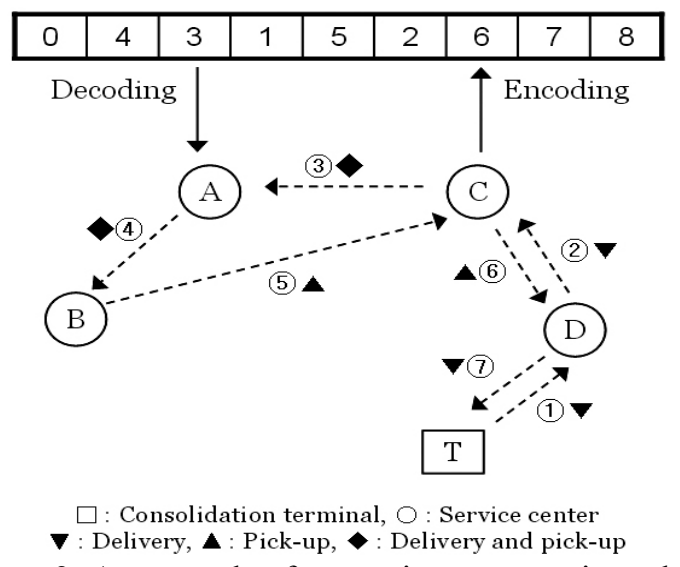

Figure 2. An example of a genetic representation scheme and the corresponding tour sequence.

length $(2 n+1)$ and the value of each element represents the tour sequence. If any node $n+k$ is positioned just after node $k$, it means that pick-up and delivery processes at service center $k$ are simultaneously performed. Figure 2 shows an example of a genetic representation scheme and the corresponding tour sequence when we assume that there are four service centers and a terminal.

Each chromosome is developed by a permutation representation which is mostly used in TSP. Four genetic operators are used in the proposed GA: cloning; parent selection; crossover; and mutation operators. The cloning operator copies some of the best current chromosomes to the new population; a binary tournament selection method for a parent selection is used, which begins by forming two teams of chromosomes. Each team consists of two chromosomes randomly drawn from the current population. The best chromosomes, selected from each of the two teams, are chosen for crossover operations. As such, two offsprings are generated and entered into the new population. Applied is a partial-mapped crossover (PMX) which is viewed as an extension of two point crossover for binary string to permutation representation. It uses a special repairing procedure to resolve the illegitimacy caused by the simple two point crossover. Then, reciprocal exchange mutation is adopted as mutation operator.

The decoded chromosome generates a candidate solution and its fitness value based on fitness function. The objective function in the proposed model, which was defined as the expression (1), is used as the fitness function. $\Delta \mathrm{d} t_{j}, \Delta p t_{j}, \Delta T$ can easily be calculated from the tour sequence corresponded to a chromosome. The overall procedures are coded in Delphi 7.0.

\section{AN EXAMPLE PROBLEM}

An illustrative example is provided to verify the appropriateness of suggested problem and evaluate the performance of the algorithm. The example problem is generated from the real situation of a company in Korea with six consolidation terminals and 500 service centers. Average daily amounts of delivery and pick-up for each

Table 1. Pick-up and delivery amount.z.

(a) Scenario I

\begin{tabular}{|c|c|c|c|c|c|c|c|}
\hline $\begin{array}{r}\text { Service } \\
\text { Center }\end{array}$ & A & B & C & D & E & F & G \\
\hline \hline $\mathrm{D}$ & 160 & 20 & 120 & 20 & 60 & 40 & 400 \\
\hline$P$ & 200 & 40 & 100 & 20 & 80 & 20 & 500 \\
\hline $\mathrm{b}_{\mathrm{j}}$ & 0.2 & 0.1 & 0.2 & 0.1 & 0.1 & 0.1 & 0.3 \\
\hline $\mathrm{a}_{\mathrm{j}}$ & 0.02 & 0.01 & 0.02 & 0.01 & 0.01 & 0.01 & 0.03 \\
\hline
\end{tabular}

(b) Scenario II

\begin{tabular}{|c|c|c|c|c|c|c|c|}
\hline $\begin{array}{r}\text { Service } \\
\text { Center } \\
\text { Type }\end{array}$ & $\mathrm{A}$ & $\mathrm{B}$ & $\mathrm{C}$ & $\mathrm{D}$ & $\mathrm{E}$ & $\mathrm{F}$ & $\mathrm{G}$ \\
\hline \hline $\mathrm{D}$ & 160 & 20 & 40 & 400 & 60 & 120 & 20 \\
\hline $\mathrm{P}$ & 200 & 40 & 20 & 500 & 80 & 100 & 20 \\
\hline $\mathrm{b}_{\mathrm{j}}$ & 0.2 & 0.1 & 0.1 & 0.3 & 0.1 & 0.2 & 0.1 \\
\hline $\mathrm{a}_{\mathrm{j}}$ & 0.02 & 0.01 & 0.01 & 0.03 & 0.01 & 0.02 & 0.01 \\
\hline
\end{tabular}

(c) Scenario III

\begin{tabular}{|c|c|c|c|c|c|c|c|}
\hline $\begin{array}{r}\text { Service } \\
\text { Center }\end{array}$ & A & B & C & D & E & F & G \\
\hline \hline$D$ & 400 & 20 & 120 & 20 & 60 & 40 & 160 \\
\hline$P$ & 500 & 40 & 100 & 20 & 80 & 20 & 200 \\
\hline $\mathrm{b}_{\mathrm{j}}$ & 0.3 & 0.1 & 0.2 & 0.1 & 0.1 & 0.1 & 0.2 \\
\hline $\mathrm{a}_{\mathrm{j}}$ & 0.03 & 0.01 & 0.02 & 0.01 & 0.01 & 0.01 & 0.02 \\
\hline
\end{tabular}

Table 2. Travel time matrix between consolidation terminal and service centers.

(unit: $\min$.)

\begin{tabular}{|c|c|c|c|c|c|c|c|c|}
\hline & T & A & B & C & D & E & F & G \\
\hline \hline T & 0 & 18 & 43 & 45 & 30 & 58 & 61 & 92 \\
\hline *A' $^{\prime}$ & & 0 & 25 & 30 & 29 & 50 & 59 & 83 \\
\hline B' & & & 0 & 11 & 48 & 58 & 74 & 87 \\
\hline C' $^{\prime}$ & & & & 0 & 55 & 69 & 64 & 100 \\
\hline D' & & & & & 0 & 29 & 34 & 63 \\
\hline E' & & & & & & 0 & 22 & 34 \\
\hline F' & & & & & & & 0 & 38 \\
\hline G' & & & & & & & & 0 \\
\hline
\end{tabular}

※ *A' means a pick-up node corresponded to the delivery node $\mathrm{A}$. 
service center are given in Table 1 with three different scenarios I, II, and III. Table 1(a), which reflects the current operation, shows that larger orders are placed at the service centers located far away from the consolidation terminal. Tables 1(b) and (C) are also constructed for the service centers, which are located in the middle and in the near of the terminal with larger pick-up and delivery amounts.

Average travel times between a consolidation terminal and service centers are shown in Table 2. When a line-haul vehicle drops by a service center, it is assumed a setup takes 15 minutes and 0.05 minutes of package handling is required for each package. A setup time remains constant even when package loading and unloading tasks are performed in the same service center. An incremental profit for an additional package is $\$ 0.5$, and a loss incurred by travel time increase is $\$ 20$ per unit time. The value of an index reflecting the effect of tour time on tour cost is also set at 2.0.

\section{AN IMPLEMENTATION RESULTS AND DISCUSSION}

Implementation results are presented as the following. The parameter values for GA algorithm are given in the following:

- Population size equals to 300 .

Table 3. The GA results with current operation data.

(a) Current operation

\begin{tabular}{|c|c|c|c|c|c|c|c|}
\hline & & $\begin{array}{l}\text { Arrival } \\
\text { Time }\end{array}$ & $\begin{array}{l}\text { Delivery } \\
\text { Amount }\end{array}$ & $\begin{array}{l}\text { Pick-up } \\
\text { Amount }\end{array}$ & $\begin{array}{l}\text { Loading/Unloading } \\
\text { Time(Min) }\end{array}$ & $\begin{array}{l}\text { Setup Time } \\
\text { (Min) }\end{array}$ & $\begin{array}{l}\text { Departure } \\
\text { Time }\end{array}$ \\
\hline \multicolumn{2}{|c|}{ Terminal(T) } & & & & & & $0: 00: 00$ \\
\hline $\mathrm{A}$ & \multirow{2}{*}{$\bullet$} & \multirow{2}{*}{$0: 18: 00$} & 160 & & \multirow[b]{2}{*}{18} & \multirow{2}{*}{15} & \multirow{2}{*}{$0: 51: 00$} \\
\hline$A^{\prime}$ & & & & 200 & & & \\
\hline $\mathrm{B}$ & \multirow{2}{*}{$\diamond$} & \multirow{2}{*}{$1: 16: 00$} & 20 & & \multirow{2}{*}{3} & \multirow{2}{*}{15} & \multirow{2}{*}{$1: 34: 00$} \\
\hline $\mathrm{B}^{\prime}$ & & & & 40 & & & \\
\hline $\mathrm{C}$ & \multirow{2}{*}{$\diamond$} & \multirow{2}{*}{$1: 45: 00$} & 120 & & \multirow{2}{*}{11} & \multirow{2}{*}{15} & \multirow{2}{*}{$2: 11: 00$} \\
\hline $\mathrm{C}^{\prime}$ & & & & 100 & & & \\
\hline $\mathrm{D}$ & \multirow{2}{*}{$\bullet$} & \multirow{2}{*}{$3: 06: 00$} & 20 & & \multirow{2}{*}{2} & \multirow{2}{*}{15} & \multirow{2}{*}{$3: 23: 00$} \\
\hline $\mathrm{D}^{\prime}$ & & & & 20 & & & \\
\hline E & \multirow{2}{*}{$\bullet$} & \multirow{2}{*}{$3: 52: 00$} & 60 & & \multirow{2}{*}{7} & \multirow{2}{*}{15} & \multirow{2}{*}{$4: 14: 00$} \\
\hline E' & & & & 80 & & & \\
\hline F & $\bullet$ & $4: 36: 00$ & 40 & 20 & \multirow[t]{2}{*}{3} & 15 & \multirow[t]{2}{*}{$4: 54: 00$} \\
\hline$F^{\prime}$ & \multirow{2}{*}{$\diamond$} & \multirow[b]{2}{*}{$5: 32: 00$} & 400 & 20 & & & \\
\hline G & & & 400 & 500 & 45 & 15 & $6: 32: 00$ \\
\hline & & $8: 04: 00$ & 820 & 960 & & & \\
\hline
\end{tabular}

(b) The GA results

\begin{tabular}{|c|c|c|c|c|c|c|c|}
\hline & & $\begin{array}{l}\text { Arrival } \\
\text { Time }\end{array}$ & $\begin{array}{l}\text { Delivery } \\
\text { Amount }\end{array}$ & $\begin{array}{l}\text { Pick-up } \\
\text { Amount }\end{array}$ & $\begin{array}{c}\text { Loading/Unloading } \\
\text { Time(Min) }\end{array}$ & $\begin{array}{l}\text { Setup Time } \\
\text { (Min) }\end{array}$ & $\begin{array}{l}\text { Departure } \\
\text { Time }\end{array}$ \\
\hline \multicolumn{2}{|c|}{ Terminal(T) } & & & & & & $0: 00: 00$ \\
\hline $\mathrm{C}$ & $\nabla$ & $0: 45: 00$ & 122 & & 6.12 & 15 & $1: 06: 07$ \\
\hline $\mathrm{B}$ & $\boldsymbol{\nabla}$ & $1: 17: 07$ & 20 & & 0.98 & 15 & $1: 33: 07$ \\
\hline A & $\boldsymbol{\nabla}$ & $1: 58: 07$ & 155 & & 7.72 & 15 & $2: 20: 51$ \\
\hline $\mathrm{D}$ & $\boldsymbol{\nabla}$ & $2: 49: 51$ & 19 & & 0.97 & 15 & $3: 05: 49$ \\
\hline $\mathrm{C}^{\prime}$ & $\Delta$ & $4: 00: 49$ & & 145 & 7.25 & 15 & $4: 23: 05$ \\
\hline B' & $\Delta$ & $4: 34: 05$ & & 53 & 2.65 & 15 & $4: 51: 44$ \\
\hline $\mathrm{A}^{\prime}$ & $\Delta$ & $5: 16: 44$ & & 399 & 19.95 & 15 & $5: 51: 42$ \\
\hline D' & $\boldsymbol{\Delta}$ & $6: 20: 42$ & & 19 & 0.97 & 15 & $6: 36: 40$ \\
\hline $\mathbf{E}$ & \multirow{2}{*}{$\bullet$} & \multirow{2}{*}{$7: 05: 40$} & 58 & & 2.90 & \multirow{2}{*}{15} & \multirow{2}{*}{$7: 28: 52$} \\
\hline E' & & & & 106 & 5.28 & & \\
\hline $\mathbf{G}$ & \multirow{2}{*}{$\diamond$} & \multirow{2}{*}{$8: 02: 52$} & 370 & & 18.48 & \multirow{2}{*}{15} & \multirow{2}{*}{$9: 20: 13$} \\
\hline $\mathbf{G}^{\prime}$ & & & & 877 & 43.85 & & \\
\hline $\mathbf{F}$ & \multirow{2}{*}{$\bullet$} & \multirow{2}{*}{$9: 58: 13$} & 38 & & 1.88 & \multirow{2}{*}{15} & \multirow{2}{*}{$10: 16: 38$} \\
\hline F' & & & & 31 & 1.53 & & \\
\hline \multicolumn{2}{|c|}{ Terminal(T) } & $11: 17: 38$ & 782 & 1630 & & & \\
\hline \multicolumn{8}{|c|}{ Incremental Profit $=\$ 108.16$} \\
\hline
\end{tabular}


- Maximum number of generations is 200 .

- Cloning rate is set at $2 \%$.

- Crossover rate and mutation rate are $50 \%$ and $1 \%$, respectively.

Table 3 and Figure 3 show the results of the proposed algorithm applied to the current operation with input data in Table 1(a). In the Table 3, terminal T means consolidation terminal. A implies delivery node, and A' denotes pick-up node. In the Figure 3(a) shows a current operation of line-haul vehicle. A pick-up and delivery truck starts from terminal $\mathrm{T}$ at $0: 00 \mathrm{AM}$, and travels service center $A, B, C, \cdots$ to $G$, then returns to terminal T 8 : 04AM. Figure 3(b) shows changed tour sequence after applying the GA algorithm. The tour sequence is T-C-B-A-D-C-B-A-D-E-G-F-T.

Figure 4 also shows a screen-captured image of implemented results. In the 92th generation, a steady state conditions are reached with a maxim profit, whose tour sequence is shown in Figure 3(b).

It is observed that the solution generates a tour with daily incremental profit of $\$ 108.16$ and 11.28 hours

Table 4. The GA test results with input data in scenario II and III.

(a) Results for scenario II

\begin{tabular}{|c|c|c|c|c|c|c|c|}
\hline & & $\begin{array}{l}\text { Arrival } \\
\text { Time }\end{array}$ & $\begin{array}{l}\text { Delivery } \\
\text { Amount }\end{array}$ & $\begin{array}{l}\text { Pick-up } \\
\text { Amount }\end{array}$ & $\begin{array}{c}\text { Loading/Unloading } \\
\text { Time(Min) }\end{array}$ & $\begin{array}{l}\text { Setup Time } \\
\text { (Min) }\end{array}$ & $\begin{array}{l}\text { Departure } \\
\text { Time }\end{array}$ \\
\hline \multicolumn{2}{|c|}{ Terminal(T) } & & & & & & $0: 00: 00$ \\
\hline$E^{\prime}$ & $\Delta$ & $0: 58: 00$ & & 52 & 2.60 & 15 & $1: 15: 36$ \\
\hline $\mathrm{G}$ & \multirow{2}{*}{$\diamond$} & \multirow{2}{*}{$1: 49: 36$} & 21 & & 1.03 & \multirow{2}{*}{15} & \multirow{2}{*}{$2: 06: 12$} \\
\hline $\mathrm{G}^{\prime}$ & & & & 11 & 0.55 & & \\
\hline $\mathrm{F}$ & \multirow{2}{*}{$\diamond$} & \multirow{2}{*}{$2: 44: 12$} & 126 & & 6.28 & \multirow{2}{*}{15} & \multirow{2}{*}{$3: 08: 03$} \\
\hline$F^{\prime}$ & & & & 51 & 2.55 & & \\
\hline $\mathrm{E}$ & $\nabla$ & $3: 30: 03$ & 61 & & 3.02 & 15 & $3: 48: 05$ \\
\hline $\mathrm{B}^{\prime}$ & $\Delta$ & $4: 46: 05$ & & 54 & 2.70 & 15 & $5: 03: 47$ \\
\hline $\mathrm{C}$ & $\nabla$ & $5: 14: 47$ & 39 & & 1.92 & 15 & $5: 31: 42$ \\
\hline $\mathrm{B}$ & $\nabla$ & $5: 42: 42$ & 19 & & 0.95 & 15 & $5: 58: 40$ \\
\hline $\mathrm{C}^{\prime}$ & $\Delta$ & $6: 09: 40$ & & 29 & 1.43 & 15 & $6: 26: 06$ \\
\hline $\mathrm{D}$ & \multirow{2}{*}{$\diamond$} & \multirow{2}{*}{$7: 21: 06$} & 347 & & 17.37 & \multirow{2}{*}{15} & \multirow{2}{*}{$8: 51: 22$} \\
\hline $\mathrm{D}^{\prime}$ & & & & 1158 & 57.83 & & \\
\hline $\mathrm{A}$ & \multirow{2}{*}{$\diamond$} & \multirow{2}{*}{$9: 20: 22$} & 131 & & 6.55 & \multirow{2}{*}{15} & \multirow{2}{*}{$10: 10: 00$} \\
\hline $\mathrm{A}^{\prime}$ & & & & 562 & 28.07 & & \\
\hline \multicolumn{2}{|c|}{ Terminal(T) } & $10: 28: 00$ & 744 & 1917 & & & \\
\hline \multicolumn{8}{|c|}{ Incremental Profit $=\$ 324.81$} \\
\hline
\end{tabular}

(b) Results for scenario III

\begin{tabular}{|c|c|c|c|c|c|c|c|}
\hline & & $\begin{array}{l}\text { Arrival } \\
\text { Time }\end{array}$ & $\begin{array}{l}\text { Delivery } \\
\text { Amount }\end{array}$ & $\begin{array}{l}\text { Pick-up } \\
\text { Amount }\end{array}$ & $\begin{array}{c}\text { Loading/Unloading } \\
\text { Time(Min) }\end{array}$ & $\begin{array}{l}\text { Setup Time } \\
\text { (Min) }\end{array}$ & $\begin{array}{l}\text { Departure } \\
\text { Time }\end{array}$ \\
\hline \multicolumn{2}{|c|}{ Terminal(T) } & & & & & & $0: 00: 00$ \\
\hline$E$ & \multirow{2}{*}{$\diamond$} & \multirow{2}{*}{$0: 58: 00$} & 62 & & 3.10 & \multirow{2}{*}{15} & \multirow{2}{*}{$1: 18: 45$} \\
\hline$E^{\prime}$ & & & & 53 & 2.65 & & \\
\hline A & $\nabla$ & $2: 08: 45$ & 385 & & 19.25 & 15 & $2: 43: 01$ \\
\hline $\mathrm{B}^{\prime}$ & $\Delta$ & $3: 08: 01$ & & 46 & 2.28 & 15 & $3: 25: 18$ \\
\hline $\mathrm{C}$ & \multirow{2}{*}{$\diamond$} & \multirow{2}{*}{$3: 36: 18$} & 117 & & 5.82 & \multirow{2}{*}{15} & \multirow{2}{*}{$4: 03: 32$} \\
\hline$C^{\prime}$ & & & & 128 & 6.40 & & \\
\hline B & $\nabla$ & $4: 14: 32$ & 19 & & 0.97 & 15 & $4: 30: 31$ \\
\hline $\mathrm{F}$ & \multirow{2}{*}{$\diamond$} & \multirow{2}{*}{$5: 44: 31$} & 40 & & 1.98 & \multirow{2}{*}{15} & \multirow{2}{*}{$6: 02: 34$} \\
\hline$F^{\prime}$ & & & & 21 & 1.07 & & \\
\hline $\mathrm{G}$ & \multirow{2}{*}{$\diamond$} & \multirow{2}{*}{$6: 40: 34$} & 157 & & 7.83 & 15 & $7: 15: 29$ \\
\hline $\mathrm{G}^{\prime}$ & & & & 242 & 12.07 & & \\
\hline $\mathrm{D}$ & \multirow{2}{*}{$\diamond$} & \multirow{2}{*}{$8: 18: 29$} & 19 & & 0.95 & \multirow{2}{*}{15} & \multirow{2}{*}{$8: 35: 54$} \\
\hline $\mathrm{D}^{\prime}$ & & & & 30 & 1.47 & & \\
\hline $\mathrm{A}$ & $\nabla$ & $9: 04: 54$ & 1378 & & 68.90 & 15 & $10: 28: 49$ \\
\hline \multicolumn{2}{|c|}{ Terminal(T) } & $10: 46: 49$ & 2177 & 520 & 68.90 & 15 & $10: 28: 49$ \\
\hline \multicolumn{8}{|c|}{ Incremental Profit $=\$ 310.94$} \\
\hline
\end{tabular}




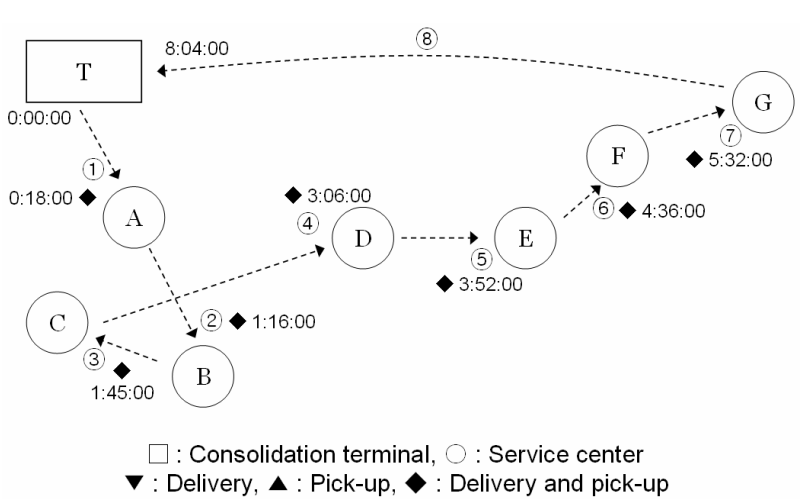

(a) Current operation

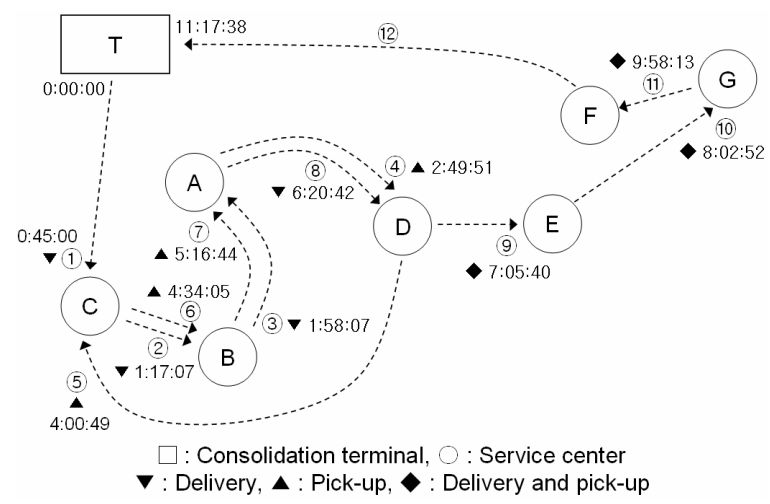

(b) GA results

Figure 3. Tour sequence for GA results.

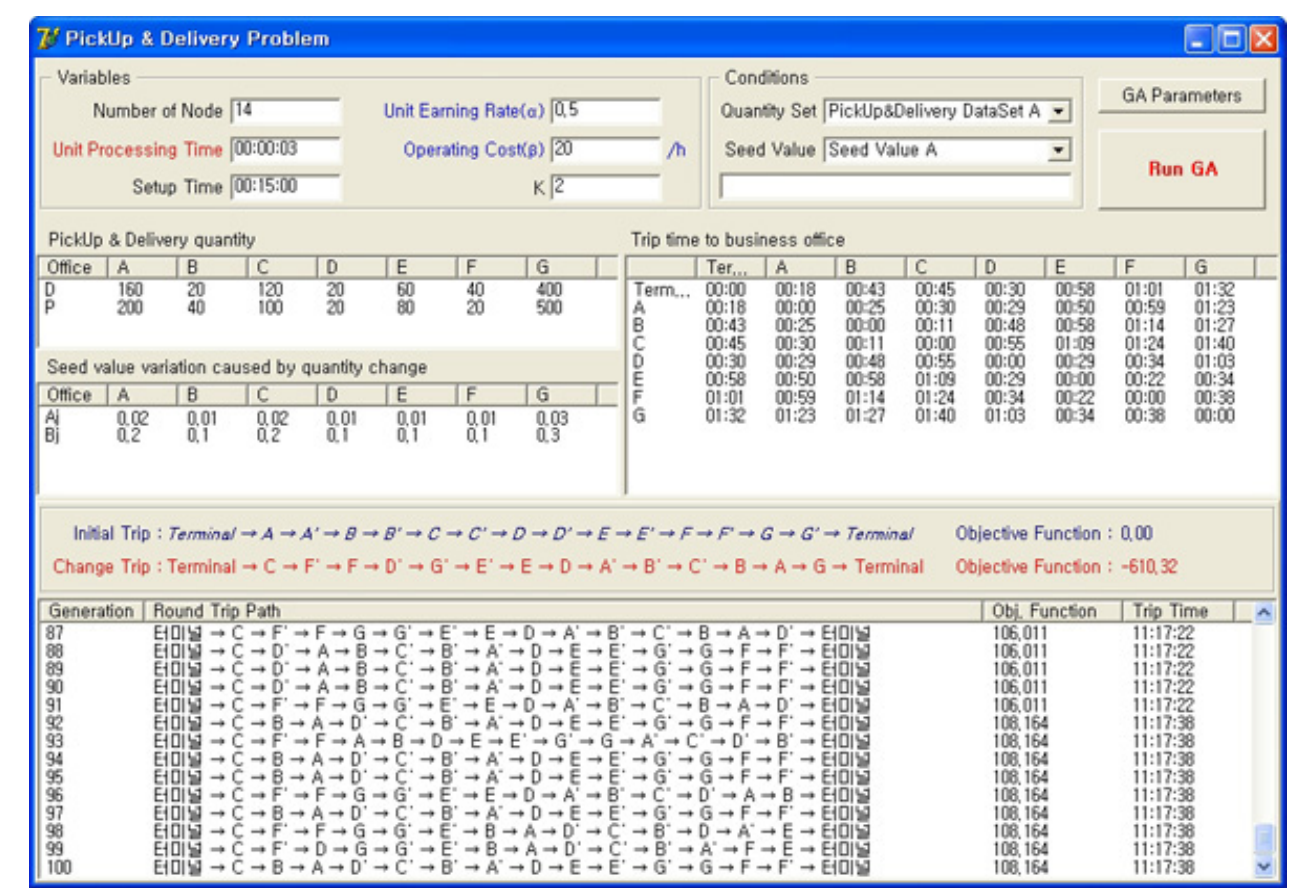

Figure 4. An example of the screen-captured image of the implemented results.

while it takes about 8 hours for completing the current tour. The GA test results with input data in Tables 1(b) and (c) are also shown in Table 4. As intended, the route is reconfigured to generate a maximum profit while sacrificing travel time. A sensitivity test may be required to tradeoff between increased profit and increased travel time.

From Tables 3 and 4, it may be observed that a tour is constructed according to pick-up and delivery amounts for each service center. Considering the operation of the corresponded consolidation terminal, it is suggested to add new restriction of the upper bound for total tour time to the proposed model.

This study proposes an approach to the design of express courier service networks to raise the profitability from the perspective of revenue increase instead of cost reduction. A PTP problem with pick-up and delivery is converted to TSPs and its solution procedure based on
GA is developed. Several difficulties have been encountered in parameter estimation, and a wide variety of simulation experiments have been conducted for parameter estimation.

As a further research, a better-performing solution algorithm needs to be investigated. It is also of great interest to examine a network reconfiguration of PDPs when multiple line-haul vehicles need to be operated to cope with larger package orders. In that case, a PDPs may be transformed to multiple-TSPs.

\section{CONCLUSIONS}

This study proposes an approach to the design of express courier service networks to raise the profitability 
from the perspective of revenue increase instead of cost reduction. A PTP problem with pick-up and delivery is converted to TSPs and its solution procedure based on GA is developed. Several difficulties have been encountered in parameter estimation, and a wide variety of simulation experiments have been conducted for parameter estimation.

As a further research, a better-performing solution algorithm needs to be investigated. It is also of great interest to examine a network reconfiguration of PDPs when multiple line-haul vehicles need to be operated to cope with larger package orders. In that case, a PDPs may be transformed to multiple-TSPs.

\section{ACKNOWLEDGMENT}

This research was financially supported by the Ministry of Education, Science Technology (MEST) and Korea Institute for Advancement of Technology (KIAT) through the Human Resource Training Project for Regional Innovation.

\section{REFERENCES}

Balas, E. (1989), The prize collecting travelling salesman problem, Networks, chapter 19, 621-636.

Bodin, L., Golden, B., Assad, A. and Ball, M. (1983), Routing and scheduling of vehicles and crews: The state of the art, Computers and Operations Research, 10(2), 63-211.

Cheung, W., Leung, L. C. and Wong, Y. M. (2001), Strategic service network design for DHL Hong Kong. Interfaces, 31(4), 1-14.

Dell'Amico, M., Maffioli, F., and Värbrand, P. (1995), On prize-collecting tours and the asymmetric travelling salesman problem, International Transactions in Operational Research, 2(3), 297-308.
Feillet, D., Dejax, P. and Gendreau, M. (2005), Travelling salesman problems with profits, Transportation Science, 39(2), 188-205.

Fischetti, M. and Toth, P. (1988), An additive approach for the optimal solution of the prize-collecting travelling salesman problem, Vehicle Routing: Methods and Studies (B. L. Golden and A. A. Assad, eds), Elsevier Science Publishers, B.V., 319-343.

Gen, M. and Cheng, R. (2000), Genetic Algorithms and Engineering Optimization, New York: Wiley

Goldberg, D. E. (1989), Genetic Algorithms in Search, Optimization and Machine Learning, Reading, MA: Addison Wesley.

Ko, C. S., Min, H., and Ko, H. J. (2007), Determination of cutoff time for express courier services: A genetic algorithm approach, International Transactions in Operational Research, 14(2), 159-177.

Leung, J. M. Y., Magnanti, T. L., and Singhal, V. (1990), Routing in point-to-point delivery systems: formulations and solution heuristics, Transportation Science, 24(4), 245-260.

Min, H. (1994), Location analysis of international consolidation terminals using the analytic hierarchy process, Journal of Business Logistics, 15(2), 25-44.

Powell, W. B. and Sheffi, Y. (1983), The load planning problem of motor carriers: problem description and a proposed solution approach, Transportation Research, 17A(6), 471-480.

Powell, W. B. (1986), A local improvement heuristic for the design of less-than-truckload motor carrier networks, Transportation Science, 20(4), 246-257.

Schneider, J. B., Symons, J. G., and Goldman, M. (1972), Planning transportation terminal systems in urban regions, Transportation Research, 6(3), 257-273.

Tasgetiren, M. F. and Smith, A. E. (2000), A genetic algorithm for the orienteering problem, Proceedings of 2000 Congress Evolutionary Computation, San Diego, CA, 1190-1195. 